\title{
Oligosaccharides from Coprophilous fungi: An emerging functional food with potential
} health-promoting properties: a recent appraisal

Jeff Okinda Ojwach ${ }^{\mathbf{1} 2 *}$, Adegoke Isiaka Adetunji ${ }^{2}$, Taurai Mutanda ${ }^{3}$ and Samson Mukaratirwa ${ }^{2,4}$

${ }^{1}$ Department of Biodiversity and Conservation Biology, Faculty of Natural Science, University of the Western Cape, Private Bag X17 Bellville 7530, South Africa.

${ }^{2}$ School of Life Sciences, College of Agriculture Engineering and Science, University of KwaZulu-Natal (Westville Campus), Private Bag X54001, Durban 4000, South Africa.

${ }^{3}$ Centre for Algal Biotechnology, Department of Nature Conservation, Faculty of Natural Sciences, Mangosuthu University of Technology, P.O. Box 12363, Jacobs 4026, Durban, South Africa.

${ }^{4}$ One Health Center for Zoonoses and Tropical Veterinary Medicine, Ross University, School of Veterinary Medicine, P.O. Box 334, Basseterre, St. Kitts, West Indies.

\section{*Corresponding author}

Jeff Ojwach

Department of Biodiversity and Conservation Biology,

University of the Western Cape,

South Africa.

Email: ojwachj@gmail.com

Tel: +254769106474 


\begin{abstract}
Functional foods are essential food products that possess health-promoting properties for the treatment of infectious diseases. In addition, they provide energy and nutrients, which are required for growth and survival. They occur as prebiotics or dietary supplements, including oligosaccharides, processed foods, and herbal products. However, oligosaccharides are more efficiently recognized and utilized, as they play a fundamental role as functional ingredients with great potential to improve health in comparison to other dietary supplements. They are low molecular weight carbohydrates with a low degree of polymerization. They occur as fructooligosaccharide (FOS), inulooligosaccharadie (IOS), and xylooligosaccahride (XOS), depending on their monosaccharide units. Oligosaccharides are produced by acid or chemical hydrolysis. However, this technique is liable to several drawbacks, including inulin precipitation, high processing temperature, low yields, high production costs, etc. As a consequence, the application of microbial enzymes for oligosaccharide production is recognized as a promising strategy. Microbial enzymatic production of FOS and IOS occurs by submerged or solid-state fermentation in the presence of suitable substrates (sucrose, inulin) and catalyzed by fructosyltransferases and inulinases. Incorporation of FOS and IOS enriches the rheological and physiological characteristics of foods. They are used as low cariogenic sugar substitutes, suitable for diabetics, and as prebiotics, probiotics \& nutraceutical compounds. In addition, these oligosaccharides are employed as anticancer \& antioxidant agents and aid in mineral absorption, lipid metabolism, immune regulation etc. This review, therefore, focuses on the occurrence, physico-chemical characteristics, and microbial enzymatic synthesis of FOS and IOS from coprophilous fungi. In addition, the potential health benefits of these oligosaccharides were discussed in detail.
\end{abstract}

Keywords: Oligosaccharides; Fructooligosaccharides; Inulooligosaccharides; Inulinase; Fructosyltransferase; Coprophilous fungi. 


\section{Introduction}

The design of food products that confer health-promoting properties is emerging and there is a growing acceptance that functional food can lead to disease prevention, well-being, and treatment [1]. Ideally, all food is functional in that, they provide energy and nutrients necessary for growth and survival [2]. Due to advances and desires in food technology and the emerging scientific evidence linking diet to disease, there is a need to address the consumption of functional foods with health-promoting properties besides basic nutrition [3]. Food supplements with healthpromoting properties help in gut manipulation and composition towards a salutary regimen [4]. This increases the proliferation of endogenous Bifidobacterium and Lactobacillus composition by fermenting short-chain fatty acid (SCFAs) in the colon, thereby creating a prebiotic effect [5].

Prebiotics are non-digestible food ingredients (including polysaccharides and oligosaccharides) that affect the host by selective stimulation of growth and/or of one or a limited number of bacteria in the gut and thus improves health [6]. Prebiotic therapies have been recognized for the treatment of gut-related illnesses such as relief of constipation, insulin resistance, diarrhea suppression, obesity, and some cardiovascular diseases associated with dyslipidemia [7]. For a food ingredient to be considered as a prebiotic, it must resist gastric metabolism and hydrolysis from enzymatic activity [5, 8, 9]. Secondly, the oligomers must be fermented by intestinal microbes and also stimulate the activity of selective bacteria in the colon [10].

In addition to the prebiotic effect, these food ingredients are still important due to their nutraceutical effects by possessing health or medical benefits including prevention or treatment of diseases [11]. Such products include dietary supplements such as oligosaccharides, isolated nutrients, specific diets, genetically engineered foods, herbal products, and processed foods [1214]. Specifically, these food products include oligosaccharides, which are dietary carbohydrates and play a fundamental role as functional ingredients when compared to probiotics, sugars, polyunsaturated fatty acids, and peptides. The requisite end products of carbohydrates metabolism are short-chain fatty acids. These include butyric acid, acetic acid, and propionic acid, which are used up by host organisms as a source of energy [15].

Microbes are also documented widely as an alternative source of oligosaccharides production [16-18]. Currently, knowledge on carbohydrate fermentation in the gut microbiome shows that the health benefits of dietary fiber and prebiotics are not linked to stimulation of selective 
bacteria, but attributed to the capacity of intestinal microbiomes for bioconversion of oligosaccharides to short-chain fatty acids, (SCFA) [19]. Oligosaccharides are sugar combinations with the degree of polymerization $\left(\mathrm{DP}_{3}\right.$ to $\left.\mathrm{DP}_{10}\right)$, and are from plant inulin or produced commercially from sucrose as substrate [20]. In the first approach, inulin is cleaved from chicory randomly by microbial endoinulinase (EC 3.2.1.7), yielding oligofructosides [21]. In the second approach, sugar cane is fructosylated to $\mathrm{GF}_{2}, \mathrm{GF}_{3}$, and $\mathrm{GF}_{4}$ by $\beta$-fructofrunosidases (EC 3.2.1.26) or $\beta$-fructosyltransferases (EC 2.4.1.100) from fungal genera including Aureobasidium and Aspergillus [22, 23].

Prebiotic oligosaccharides are manufactured majorly in three ways: isolation from plant sources [24-26], enzymatic degradation of polysaccharides[27, 28], microbial production, or enzymatic synthesis [29]. A combination of probiotics and prebiotics are used together to take advantage of synergic effects in food application and biotechnology and the mixture is called symbiotic [30]. The health effects of functional foods, including their nutraceutical effect, have led to numerous studies on food-grade oligosaccharides which include fructooligosaccharides (FOS), inulooligosaccharides (IOS), xylooligosaccharides (XOS), galactooligosaccharides (GOS), amongst classes of prebiotics [31-36]. To produce food-based FOS and IOS, microbial enzymatic synthesis remains attractive and desirable approach, as they are less toxic to the environment, emit fewer emission and by-products, and operates at low temperatures [37]. The present review focuses on the occurrence and microbial enzymatic production of FOS and IOS from new coprophilous fungi. Thereafter, the potential health benefits of the oligosaccharides were discussed explicitly.

\section{Coprophilous fungi-Habitats and occurrence}

Coprophilous fungi, also known as fimicolous species are dung-loving fungi, found on dung substratum [38, 39]. They are a group of saprophytic fungi adapted to life on dung and fecal pellets of herbivores (Fig. 1) [40]. These fungi rely on terrestrial warm-blooded herbivores to complete their life cycle [41]. When herbivores graze on vegetation, they ingest spores from coprophilous and non-coprophilous fungi along with vegetation [42]. The spores of noncoprophilous fungi are killed by high temperatures and gastric juices in the gastrointestinal tract 
of the herbivores while coprophilous fungal spores survive in the gut, undergo hydrolysis, and are passed out to germinate, grow and fruit on dung [43]. However, any dung can yield fungi, but herbivore dung has been regarded as the best source of coprophilous fungi. This fungus has a cosmopolitan distribution, as they occur in many herbivore species around the world $[44,45]$.

Coprophilous fungi are classified into different morphological keys: key one (MJR) belongs to coprophilous ascomycetes that are a very diverse group with many species yet to be discovered [46]. The second key includes the original plectomycete key (RW), which contains fungi that are not biased on herbivore dung but occur in horn, hair, and cadavers as well as on carnivore dung [46]. The third key (RW, p52) belongs to basidiomycetes of dung-associated debris. The fourth key (MJR, p63) includes zygomycetes, found to appear first on freshly dropped dung, but soon disappear [46].

Herbivore dung is a rich substratum of coprophilous fungi and supports high species diversity. Fruiting bodies of dung fungi appear in succession mostly following the sequence: Zygomycotina, Ascomycotina, and Basidiomycotina [42]. Dung fungi play a vital role in the mineralization and decomposition of herbivore dung while, some display few modifications peculiar to their habitat $[42,47]$.

\section{Potential of coprophilous fungi in oligosaccharide production}

Fungi that grow on herbivore dung are full of fiber from dung biomass and have potential cellulolytic activity [48]. Cellulose is a linear glucose polymer linked by $\beta$-1,4-glycosidic bond, forming a large component of plant biomass [38]. Herbivore dung contains high amounts of readily available complex carbohydrates, made up of cellulose, hemicellulose, pectin, lignin, and high nitrogen content. In addition, they have a high moisture content, vitamin, growth factors, and minerals [40, 47]. The ruminal ecosystem represents the most potent fibrolytic fermentation system known. It is composed of a diverse population of obligate anaerobic fungi, bacteria, and protozoa [49]. Coprophilous fungi in the rumen produce potent fibrolytic enzymes that can degrade recalcitrant plant polymers [48]. The gut metabolism of herbivores is specifically adapted for highly specialized microbial processing of complex plant polysaccharides ingested [49]. Since dung is egested with plant material, cells, and interwoven matrix of plant polymers 
from the herbivore rumen due to their incomplete digestion and consequently microbes on dung use them up. The array of enzymes in the rumen is not only from gut microbial diversity but also from the multiplicity of fibrolytic enzymes produced by individual microbes [49].

Recently, from our laboratory, sixty-one autochthonous coprophilous fungal strains were screened for the ability to biotransform sucrose and inulin into FOS and IOS by producing fructosyltransferase and inulinase, respectively. The isolates exhibited high transfructosylating activity and produced short-chain FOSs including $\mathrm{GF}_{3}, \mathrm{GF}_{4}$, and $\mathrm{GF}_{5}$. Coprophilous fungus isolate XOPB-48 identified as Aspergillus niger showed a robust combination of high extracellular transferase activity following HPLC-RI analysis [50]. The enzyme exhibited a good transfructosylating activity by catalyzing sucrose to FOS with an I/S ratio of 1.77 . The utilization of herbivore dung as a cheap and readily available bioresource raw material allows the development of low-cost bioprocess for FOS and IOS production. In addition, the complex carbohydrate and bioactive characteristics of cellulose and lignin in dung biomass, therefore, displays unexplored reservoir as it can produce substrates with transfructosylating activity.

\section{Oligosaccharides}

Oligosaccharides form part of new functional food with great potential to improve health due to their physicochemical characteristics [51]. They are classified as glycosides since they contain 310 sugars moieties [52]. Oligosaccharides are carbohydrates with low molecular weight and low DP [51]. Carbohydrates are the main group that forms oligosaccharides; their monosaccharide units include glucose, galactose, fructose, and xylose. The non-digestible oligosaccharides emanate from the survey that carbon atoms of the monosaccharides have some disposition that make osidic bonds non-digestible to hydrolytic activity of enzymes in the human intestine [53]. Oligosaccharide stability differs according to classes depending on sugar residues present and anomeric configuration [54]. Predominantly, $\beta$-linkages are stronger and stable than $\alpha$-linkages, and hexoses are more strongly linked than pentoses [55]. They also have high moisture retaining capability, preventing excessive drying, and low water activity that inhibits microbial contamination [56]. 


\section{Physicochemical and functional properties of oligosaccharides}

Oligosaccharides have biofunctional and physicochemical properties that make them desirable for consumption as food ingredients or supplements [51]. Incorporation of oligosaccharides enriches the rheological and physiological characteristics of foods [57]. This is predominantly due to their water solubility and sweetness. Oligosaccharides are slightly sweeter than sucrose (0.3-0.6 times), but the sweetness is dependent on the DP, chemical array, and level of mono- and disaccharide present in the mixture [56]. The viscosity of fructooligosaccharide (FOS) solution is relatively higher than that of mono- and disaccharide (sucrose) at the same concentration [31]. They are more viscous due to their higher molecular weight [58]. They alter the amount of browning in food by recasting the freezing temperature of some foods. They control microbial contamination by absorbing water since they act as a drying agent due to their moisture-retaining capability [59]. FOSs have higher thermal stability than sucrose; they are stable within the normal $\mathrm{pH}$ range of foods ( $\mathrm{pH}$ 4.0-7.0) [27]. Their stability is dependent on ring form, sugar residue content, anomeric configuration, and linkage type. Principally $\beta$-linkages are stronger compared to $\alpha$-linkages while hexoses are strongly linked than pentoses [58].

Oligosaccharides are used as low cariogenic sugar substitutes, as they are inactivated by mouth enzymes or in the upper gastrointestinal tract to form acid or polyglucans due to their physicochemical characteristics of being less sweet, making them suitable for consumption by diabetics $[60,61]$. They show immoderately high structural diversity than oligonucleotides and oligopeptides [62].

\section{Occurrence of fructooligosaccharides}

Fructooligosaccharides are non-digestible oligosaccharides of fructose consisting of a glucose unit $(G)$ connected with fructosyl units $(F)$ at $\beta-(2 \quad 1)$ position of sucrose $[22,63,64]$. In addition, they consist of 1-kestose $\left(\mathrm{GF}_{2}\right)$ (Fig. 2a), nystose (GF3) (Fig. 2b), and 1- $\beta$-Dfructofuranosyl nystose $\left(\mathrm{GF}_{4}\right)$ (Fig. 2c), which have 1-3 fructose units' bond to the $\beta-(2,1)$ position of sucrose (Fig. 2) [31, 65, 66]. FOSs are short-chain carbohydrates, which are not digested in the upper part of the gastrointestinal tract; they are also referred to as non-digestible 
oligosaccharides $[15,67]$. The linkage type between their monosaccharide residues distinguishes FOSs.

FOS can be produced using three methods: extraction from inulin-rich plant material, enzymatic synthesis of sucrose, or degradation of inulin by enzyme hydrolysis [68-70]. However, the majority of FOS, which are food ingredients are synthesized through enzymatic degradation of inulin from plant polysaccharides or synthesized from sucrose by fructosyltransferase activity [71]. FOS is synthesized by a wide array of enzymes such as inulinases and fructosyltransferases in large-scale industrial production $[72,73]$. The various microbial and plant sources of FOS are tabulated in Table 2.

Synthesis of FOS occurs through the catalytic action of transfructosylating enzymes, which are classified into two categories: Ftase $\beta$-D-fructofuranosidase (EC 3.2.1.26) and fructosyltransferases (Ftase, EC 2.4.1.9) [23, 74]. Ftases possess both hydrolytic and transfructosylating activity, as it releases glucose molecule from sucrose by cleaving the $\beta-1,2-$ glycosidic linkage, thereby shifting the fructosyl group to sucrose, forming FOS products [73]. Ftases exhibit high transfructosylating activity by catalyzing the transfer of fructosyl moiety from one sucrose molecule to another to produce higher FOS units as major products [23]. These enzymes occur in many higher plants such as Cichorium intybus and Helianthus tuberosus that produce high levels of Ftase such as sucrose fructosyltransferase (1-SST, EC.2.4.1.99) and fructose 1-fructosyltransferase (1-FFT, EC 2.4.1.100) [75]. Fungi including Aspergillus niger ATCC 20611, Aspergillus niger AN 166, Aspergillus foetidus, Aspergillus oryzae CFR 202, and Aureobasidium pullulans CFR 77 have been largely documented to contain enzymes with both hydrolytic and transfructosylating activities [17]. Bacterial strains have also been reported to produce Ftase for FOS production, but only few species have been mentioned, which include Bacillus macerans, Lactobacillus reutri, Streptococcus mutans and Zymomonas mobilis [17, 7680].

Fructooligosaccharides are natural food products with beneficial health effects to the human colon by selectively stimulating the proliferation of Bifidobacteria and Lactobacilli while concurrently suppressing the growth of potentially pathogenic microbiota such as Clostridia [8, 15]. It is for these reasons that, FOSs have received particular attention as biofunctional food products. FOS has generated a great demand in the global food market and is generally regarded 
as safe (GRAS) [81]. Due to these properties and functionalities as alimentary canal additives, suitability for diabetics; non-cariogenic and nutraceutical compounds, they are termed prebiotics $[21,82-85]$.

Prebiotics are compounds that selectively stimulate proliferation of gut microbiota in the colon by inhibiting pathogenic microbes; protonation of potentially toxic ammonia and amines; diminution of total cholesterol in the blood; relieving constipation, triglyceride and phospholipids [86]. The human colon is one of the most colonized and metabolically active organs in the human body. It presents different bacterial composition and variability, largely due to different physicochemical conditions such as favorable $\mathrm{pH}$, slow transit time, and nutrient availability in the gut [86]. The human digestive system lacks the necessary enzyme to hydrolyze $\beta$-glycosidic linkages of sugars consumed and as such, non-digestible oligosaccharides can ferment these sugars, creating a prebiotic effect. Prebiotics also display secondary functions including mineral absorption, synthesis of vitamin B-complex, immune system activation, and non-cariogenecity [87]. The human gut ferments a range of carbohydrates that pass the small intestines and are available for fermentation in the colon [84].

\section{Chemical structure of fructooligosaccharides}

Fructooligosacchrides are inulin-derived, short-chain oligosaccharides, containing D-fructose of linear polymers and oligomers joined together by $\beta$-(1,2) linkages [88]. A glucose molecule typically resides at the end of each fructose chain, where it's linked by an $\alpha-(1,2)$ bond as in sucrose [89]. Inulin is a highly polymerized fructan with a chain length ranging from 2- 60 units and a DP of 25 with molecular distribution ranging from 11 to 60 [90]. They are depicted by the formula $\mathrm{GF}_{\mathrm{n}}$ and constitute a series of homologous oligosaccharides gleaned from sucrose. In addition, FOSs are members of the fructan group, consisting of a general glucose unit linked to several fructose units. Fructans present in nature can be distinguished based on glycosidic linkages, where fructose residues are linked together [88]. They can be divided into three: the first group is inulin, where fructose units are linked through $\beta-(2,1)$ bond; the second group are levans, which are linear fructans, and the fructose units are linked via a $\beta-(2,6)$ bond; the third 
group is graminian fructan, which is of mixed type, consisting of both $\beta-(2,1)$ and $\beta-(2,6)$ linkages between fructose units [91].

Chain length or DP has a vital role in inulin functionalities. Functional attributes of inulin and oligofructose is attributed to their chain length. Inulin has a longer chain length than oligofructose, which makes it less soluble and forms inulin microcrystals when sheared in water or milk [92]. Oligofructose is a fructose oligosaccharide containing 2-10 monosaccharide residues connected by glycosidic linkages [71]. Oligofructose is reported to have a shorter chain oligomer and possesses similar functional properties to glucose syrup or sugar [93]. Its solubility is higher than sucrose and accounts for $30-50 \%$ of sugars. Oligofructose has numerous nutritional properties such as providing crispiness to low-fat cookies, acts as a binder in nutritional or granola bars [94]. Since inulin and oligofructose have desirable functional properties, they are used together and offer dietary fiber effects, leading to reduced caloric effects in foods when compared to typical carbohydrates because they possess $\beta-(2,1)$ bonds linking fructose molecule [92].

\section{Fermentative production of fructooligosaccharides}

Studies on fermentation parameters are critical to obtaining maximum yields of FOS. The two main methods documented so far for the production of FOS include submerged fermentation (SmF) and solid-state fermentation (SSF) [95]. Numerous studies have been reported on FOS production using submerged fermentation techniques with titres in the range of grams per litre $[96,97]$. However, more recently, solid-state fermentation has been preferred as an alternative to submerged fermentation for the production of oligosaccharides with higher productivity [98]. For specific applications, SSF is viewed as a desirable approach due to its improvements in reactor designs [99, 100]. However, it's still necessary to establish the optimal conditions under SSF for maximum FOS production [101]. Numerous advantages have been associated with SSF. These include simplicity in operation, which produces high-level products after fermentation [102]. SSF uses low water consumption; requires less sterilization and permits little/no microbial contamination during product formation. In addition, it requires less capital to operate, as it uses simple equipment, less space, and agro-industrial residues as substrates that are converted to bulk 
chemicals with high volumetric products of high commercial value [31, 103]. The downstream process is easier with reduced stirring and low sterilization. However, there are also drawbacks associated with solid-state fermentation. These include the build-up of temperature, $\mathrm{pH}$, moisture, and substrate concentrations. Since it uses little water, it becomes difficult to control [84]. Moreover, the particle size of the substrate is a variable factor that presents a strong effect during the fermentation process. Since small particle increases surface area between the gas phase and microbes, they can influence the medium by making water and oxygen transfer of nutrients difficult [104]. Furthermore, media optimization is labour intensive and time-consuming for higher yields of FOS [105].

\section{Inulooligosaccharides production from inulin hydrolysis}

With the increasing demand for nutritional food, significant attention is being paid to functional foods. Aside from the basic nutrition, the functionality of food with high production value and nutraceutical effect is in great demand [21, 106]. These predominant reasons have led to the production of IOS, which is a class of prebiotic. Overwhelming consumer consciousness for healthier food has heightened the fast growth of the functional food market for IOS [107].

Inulin as a substrate can be regarded as a promising source for inulooligosaccharide production [108]. IOSs produced from inulin hydrolysis are reported to have homogeneous biochemical and physiological functions [109, 110]. Inulin with high DP has shown good prebiotic potential [108, 111]. This is due to its resistance to digestion by the gut enzymes because of the presence of fructose in their $\beta$-configuration [112]. However, the DP varies from different plant species, age of plant, climatic conditions, harvesting periods, and inulin-rich plant organic material [108]. Inulin serves as a reserve carbohydrate of vegetable and plant polysaccharides. It is found in the underground roots and tubers of dahlia (Dahlia pinnata), chicory (Cichorium intibus), Jerusalem artichoke (Helianthus tuberosus), asparagus (Asparagus racemosus) and dandelion (Taraxacum officinale) as illustrated in Fig. 4 [113]. Inulin consists of linear chains of $\beta$-(2-1)-D-fructosyl fructose links terminated by a glucose residue via a sucrose-type linkage at the reducing end [107, 114]. Regioselective reaction and mode of action of inulin with inulinases release fructose units or inulooligosaccharides $[115,116]$. (Fig. 5). There are several types of fructans such as inulin, levan, phlein, kestoses, kesto- $n$-oses and graminian [21]. However, inulin fructan is a 
potential substrate for the production of ultra-high fructose syrup (UHFS). The partial hydrolysis of inulin using endoinulinases yields oligofructose with an average DP of 4. Lower DP oligosaccharide is composed of inulobiose (F2), inulotriose (F3), inulotetraose (F4), inulopentaose (F5) and prebiotic IOS [22, 113, 117].

Inulin-type fructans have desirable properties similar to FOS. These include high sweetness intensity, as they are third sweeter as sucrose and this feature is important in foods restricted with sucrose [118]. Secondly, IOS has low calories levels, which are rarely absorbed by the upper part of the gut and consequently are not used up as an energy source, making them safe for consumption by diabetics [21]. Third, IOSs are non-cariogenic, that is, they are unused by Streptococcus mutans to form acids and $\beta$-glucan, which is insoluble and a major cause of dental caries [70]. Fourth, inulin-type fructans act as prebiotics since they promote the growth of Bifidobacteria while concomitantly suppressing the growth of potentially putrefactive microbes in the digestive tract $[21,119]$. These properties improve gut functions. The evaluation of gut microflora before and after inulin intakes is illustrated in Fig. 6.

\section{Enzyme-mediated production of inulooligosaccharides and fructooligosaccharides}

Complex carbohydrates are difficult to synthesize hence require alternative methods that can degrade polysaccharides to maximize yields. Inulin hydrolysis has been employed in the production of syrup with high fructose concentration [107]. The reaction was carried out using an acid catalyst and was found to present several shortcomings including high processing temperature, leading to high energy consumption, inulin precipitation, and microbial contamination [120]. In addition, by-products with no sweetening capabilities, resulting in overall decrease in yields were also reported. Several other drawbacks on chemical hydrolysis include extended time for refluxing, found to require acid-resistant equipment [21]. Moreover, the processes are tedious, as they involve protection, deprotection, and activation strategies to control the stereochemistry and regioselectivity of the resulting oligosaccharide, which is undesirable and unrealistic for large-scale production [121, 122]. In addition, the chemical method requires the use of hazardous \& expensive chemicals and results in low yields and high production costs. Due 
to the aforementioned challenges, the application of microbial enzymes for oligosaccharide production is recognized as an attractive strategy [27, 123].

Application of enzyme-based approach for catalytic production of oligosaccharides has been applied as an alternative technique to acid and chemical hydrolysis due to its simplicity in preparation, rapidity, and reproducibility in mild reaction conditions and easy separation of products [124]. Enzymatic approach consumes less energy, as it requires low temperatures, produce less toxins and pollutant to the environment, and produces fewer emissions \& byproducts [21, 120]. Enzymatic method has been demonstrated as a suitable approach for industrial oligosaccharide production [21, 125]. For instance, the use of inulinase has been reported to produce $95 \%$ pure fructose $[126,127]$. Other products include IOS mixture, consisting of inulotriose, inulotetraose, inulobiose, inulopentaose, and minimal glucose [21].

\section{Enzymes used for oligosaccharides' production}

Fructoligosaccharide is produced by the transfer of fructose residues to sucrose molecules by the action of fructosyltransferase (E.C.2.4.1.9), $\beta$-fructofuranosidase (E.C.3.2.1.26), or inulinase [27, 128]. Inulinases are divided into two subclasses due to their mode of action: exoinulinases (EC: 3.2.2.80), which cleaves fructose from the non-reducing sugar end of inulin through hydrolysis and is mainly used in the synthesis of ultra-high fructose syrup [129]. Endoinulinases (EC: 3.2.1.7) hydrolyses inulin into IOS [114]. IOS produced from inulin possesses corresponding physiological functions to FOS with variations in DP [130]. Numerous microorganisms including Aspergillus niger, Aspergillus ficuum, Arthrobacter sp, Penicillium purpurogenum, Bacillus macerans and Streptococcus mutans are sources of endoinulinases [78, 80]. Moulds are the most prominent groups producing endoinulinases [131]. Interestingly, few fungal species have both exo and endoinulinase properties [108]. 


\section{Fungal fructosyltransferases}

Fungal Ftases have a molecular mass ranging from 180,000 to 600,000 and are homopolymers with 2-6 monomers [132]. Fructofuranosidase isolated from Aspergillus oryzae is a monomer with a molecular weight of 87000 - 89000 [28, 84]. Several studies on transfructosylating enzymes secreted by Aspergillus and Aureobasidium produced maximum yields of FOS. The enzyme displayed both hydrolytic and transferase activity [95, 133]. Yoshikawa et al. (2006) reported Fructosyltransferase from the cell wall of Aureobasidium pullulans with high transferase activity with the lowest $\mathrm{Km}$ value for sucrose $139 \mathrm{mM}$ [134]. In fungi, Ftase 1 plays a major role in FOS formation while Ftase IV has strong hydrolytic action that may degrade FOS [84]. Several fungi species such as Aspergillus, Aureobasidium, and Penicillium are known to produce both intracellular and extracellular $\beta$-fructofuranosidase and fructosyltransferase [133, 135-139]. Predominantly, Aspergillus species have received particular interest in microbial FOS production [140, 141]. Aspergillus niger and Aspergillus oryzae have been exploited for enzyme production since they have GRAS status [132]. Other fungi such as Penicillium rugulosum and Aspergillus phoenicis CBS 294.80, which secrete a thermostable inulinase for industrial fructose production also produce a sucrose- $1^{\mathrm{F}}$-fructosyltransferase, SFT (E.C 2.4.1.99) [142, 143]. Fungal ftases have been the focal point, as numerous studies on industrial biotechnology have described the isolation and screening of intra or extracellular fructosyltransferase [133, 144]. Aspergillus japonicus with other moulds was selected after a screening exercise for the ability to produce transferase [145]. In addition, Madlov et al. (2000) selected Aspergillus pullulans and Aspergillus niger for their potential to produce fructosyltransferase [146]. Furthermore, Fernandez et al. (2007) screened seventeen filamentous fungi grown in batch cultures and compared their ability to produce $\beta$ fructofuranosidase and fructosyltransferase [147]. The findings revealed three strains of Aspergillus niger ATTC 20611, IPT-615 and Aspergillus oryzae IPT-301 as good candidates for industrial fructosyltransferase production.

Screening of new fungal isolates is always a difficult procedure due to a number of evaluations. However, numerous reports still exist on screening fungi for biotechnological application. A presumptive and indirect colorimetric plate assay was employed for screening of a filamentous fungus for transfructosylation ability [148]. The method was carried out to determine the simultaneous release of fructose and glucose from sucrose biotransformation. A glucose oxidaseperoxidase reaction using phenol and 4-aminoantipyrine was used for glucose determination. 
Fructose dehydrogenase oxidation in the presence of tetrazolium salt was used for fructose determination. The formation of a pink halo revealed the presence of glucose while blue halo formation confirmed the presence of fructose and transfructosylation activity. Other studies on screening fungal and yeast species for fructosyltransferase production have also been reported, as they are a more feasible and economic source of biocatalytic enzymes [18, 87, 149-151]. Based on these evaluations, fungal fructosyltransferase is more desirable than plant and bacterial fructosyltransferase for large-scale production of FOS. This is due to their physicochemical characteristics including minimal loss of enzyme activity, by-product inhibition, and low molecular weight, which allows easier separation of the biocatalyst from the product.

\section{Bacterial fructosyltransferases}

FOS-producing enzymes are rarely secreted among bacterial species, but notwithstanding some strains of bacteria have been reported to be inulinase producers [31]. A study by Hicke et al. (1999) reported Streptococcus mutans as the only known source of bacterial inulinase [152]. In earlier studies, cloning and sequencing of the $\beta$-D-fructosyltransferase was reported from Streptococcus salivarius. The recombinant fructosyltransferase was expressed in Escherichia coli and later purified to homogeneity [153]. The enzyme catalysed the transfer of fructosyl moiety of sucrose to multiple receptors including glucose, water, and unhydrolysed sucrose via the Ping Pong mechanism of fructosyl-enzyme intermediate [154, 155]. A transfructosylating enzyme from Bacillus macerans EG-6 produced FOS with a yield of $33 \%$ in the presence of $50 \%$ sucrose as substrate [80]. A novel strain of Bacillus licheniformis was reported to be capable of producing FOS and a polysaccharide-type levan [156, 157]. An ethanol-producing bacteria strain of Zymomonas mobilis has been reported to produce levansucrase, capable of producing FOS and levan [158]. Levansucrases are fructosyltransferases belonging to the family 68 of glycoside hydrolases, which catalyzes FOS formation and synthesis of $\beta-(2,6)$ levan [156]. In this study, extracellular levansucrase along with levan as the supernatant was used as biocatalyst in FOS sugar syrup. FOS yield of 24-34\% was obtained, comprising of 1-kestose, 6-kestose, neokestose and nystose [31]. Glucose which formed as a by-product during FOS production was found to inhibit transfructosylation reaction along with ethanol (7\%) in sucrose syrup [159]. The fructan syrup group showed prebiotic characteristics. In another study, a strain of Lactobacillus reutri 
121 was reported to produce $10 \mathrm{~g} / \mathrm{L}$ FOS (95\% 1-kestose and 5\% nystose) in the supernatant when grown on sucrose medium as a carbon source. Fructosyltransferase obtained from the strain when incubated at $17 \mathrm{~h}$ with sucrose also produced FOS and $0.8 \mathrm{~g} / \mathrm{l}$ inulin $[160,161]$. Furthermore, the effect of ten commercially available oligosaccharides was tested in vitro on the growth of Lactobacillus strains including Lactobacillus reutri C 16, Lactobacillus salivarious I 24, Lactobacillus gallinarum I 16 and Lactobacillus bevis I 25. From the investigation, oligosaccharide utilization varied among the Lactobacillus strains. Good growth of Lactobacillus was supported by isomaltooligosaccharides (IMO), GOS, and FOS. The results indicate that oligosaccharide utilization by Lactobacillus could be both strain and substrate specific [83].

\section{Microbial exoinulinases}

Inulin is a polyfructan containing linear $\beta-2,1$ linked polyfructose chain and is considered to be the most suitable substrate for enzyme production [129]. It is also considered as a renewable source of raw material in fructose syrup manufacturing and FOS production [162]. It is insoluble in water due to variations in chain length elongation and molecular weight, which varies between 3500 - 5500. Microbial inulinase (2,1- $\beta$-D-fructan fructohydrolase EC, 3.2.1.80) catalyzes inulin hydrolysis by cleaving D-fructose from non-reducing sugar ( $\beta-2,1)$ end of inulin [129]. Microbes involved in exoinulinase production include species of Penicillium, Aspergillus, Kluyveromyces, Sporotrichum, Cryptococcus, Pichia, Cladosporium, Bacillus, Pseudomonas, Xanthomonas, Sporotrichum and Candida [13, 163, 164].

\section{Microbial endoinulinases}

Microbial endoinulinases (2,1- $\beta$-D-fructan-fructan hydrolase, EC3.2.1.7) act on the internal linkage of inulin randomly to form intermediates such as inulotriose, inulotetraose and inulopentaose [21]. It is observed that similarities exist between exoinulinases and endoinulinases and this makes it difficult to separate by conventional methods. However, Native-polyacrylamide gel electrophoresis has been proposed as an efficient tool to separate enzymes showing similar characteristics [165]. Endoinulinase that is free from invertase or exoinulinase activity has been 
investigated and reported to hydrolyze inulin internal linkages and thus producing several oligosaccharides which are soluble dietary fibre with low caloric value [130].

\section{Potential health benefits of oligosaccharides}

\section{Prebiotics}

Prebiotics are biofunctional food supplements that stimulate selective growth of Lactobacilli and Bifidobacteria in the gut, leading to improved health [166]. Prebiotics creates an unfavourable environment for harmful invasive pathogens by stimulating Lactobacilli and Bifidobacteria proliferation [167]. The intestinal bacteria ferment oligosaccharides and produce large compounds of short-chain fatty acid, resulting in acidic conditions in the colon which colonize adhesive sites and secrete bacteriostatic peptides [168]. The prebiotics bacteria survive harsh acidic conditions and are adherent to mucosal walls of the gut by producing organic acids like lactic acid, which are inhibitors of many pathogenic microbes hence improving gut health [169]. Some of the major prebiotic functions are illustrated in Fig. 7.

\section{Dietary fiber effect}

Dietary fibers are plant or carbohydrates analogous that are not easily hydrolyzed in the upper part of the small intestines [170]. They contain edible plant polysaccharides remnants that cannot be easily hydrolyzed by human digestive enzymes (AACC Report 2001). The partial or complete fermentation in the large bowel is crucial in the metabolism of dietary fiber [170]. There is increasing evidence that supplementation of diet with fermentable fiber alters the gut function and structure either by modification or production of gut-derived hormones, which improve glucose homeostasis [171]. It is for this reason that oligosaccharides are associated as part of its identity, as it portrays beneficial physiological characteristics showing similarity with dietary fiber intake [94, 172]. Consumption of dietary fiber provides health benefits to humans, including the bioavailability of minerals and aid in lipid metabolism, thereby reducing risks associated with 
colon cancer and cardiovascular disease. They can be incorporated into food and drink, as they provide caloric dilution in viscous drinks and diets [71].

\section{Anticancer agent}

Diets that contain high proteins, high animal fat concentrations, and low dietary fibre concentrations are linked with colonic cancer [88]. However, oligosaccharides contribute indirectly to colon cancer prevention [55]. Oligofructose administration has been found to decrease genotoxicity [51]. Some bacterial commensals of the colon are carcinogenic and tumour promoters as a result of food metabolism [173]. In the gut, there exist two types of fermentation after ingestion of food proteolytic and saccharolytic enzymes. The latter is more favorable due to metabolic by-products formed such as acetate, SCFAs, propionate, and butyrate [174]. When a model system of the human gut was investigated after feeding of galactooligosaccharides, there was a considerable depreciation of nitroreductase, a metabolic activator and carcinogenic substance that decreases indole and isovaleric levels [15]. According to studies done by Kim et al [122], butyrate has been found to have antitumor characteristics and also up-regulate apoptosis, therefore, contributing to the prevention of colon cancer by promoting cell differentiation [84]. In another study reported by Bali et al [23], consumption of oligosaccharides was observed to reduce intestinal tumour while increasing the development of lymphoid nodules in the gutassociated lymphoid tissue (GALT). In addition, propionate has chemoprevention properties that induce an anti-inflammatory effect on colon cancer cells [175]. Another study reported the effect of starch administration on human flora-associated rats (HFA), where there was a decrease in ammonia levels and $\beta$-glucuronidase with high-level caecal butyrate observed. Butyrate which is critical for cancer reduction is not only the primary energy source for colonocytes but also helps to maintain a healthy epithelium. It can also play a large part in cancer prevention. Such interactions include activation of apoptosis, a mechanism that is inactivated in cancer cells that would normally contribute to their death and an increase in the immunogenicity of cancer cells due to an increase in the expression of proteins on the cell surface [176]. Butyrate plays a dual role of maintaining a healthy epithelium as well provides energy for colonocytes [15]. Furthermore, decrease in azomethane-induced colorectal cancer in F344 rats when fed on oligofructose diet indicates anti-cancer potential of the functional food [23]. 


\section{Mineral absorption}

To expand the knowledge of oligosaccharides in improving mineral absorption, several mechanisms have been explained. The consumption of oligosaccharides has been explained in several experimental animals [177, 178]. The dietetic fibre binds to or sequesters minerals, reducing their absorption in the ileum and their arrival in the large intestine [88]. The sequestered minerals along with fermented soluble fibre become available in the colon; high concentrations of SCFAs from colonic fermentation of oligofructose increase solubility of calcium and magnesium ions [24]. The stimulation of magnesium and calcium was also observed in dogs while in adult animals, mineral absorption was stimulated in groups receiving resistant starch or inulin diet. Moreover, there was a significant increase in calcium absorption if there was a combination of the two [179]. Bioavailability of oligosaccharides occurs largely in the colon; this is due to fermentation by commensal microbes [180]. SCFAs decrease luminal $\mathrm{pH}$, leading to an acidic environment favouring solubility of $\mathrm{Ca}^{2+}, \mathrm{Mg}^{2+}, \mathrm{Fe}^{2+}$ that maintain a homeostatic balance between $\mathrm{Fe}^{2+}$ and $\mathrm{Zn}^{2+}[84,181]$. In another study, gastrectomized experimental animals were fed with oligosaccharides. The iron uptake was found to increase, suggesting the significance of the functional food in alleviating anaemic conditions. Oligosaccharides uptake was also observed to prevent osteopenia in rats, as calcium ions stored in bones was easily absorbed [23]. Numerous benefits emanate from intestinal calcium and magnesium uptake [6].

\section{Lipid metabolism}

Animal studies carried out in mice showed that oligofructan, inulin and non-digestible (but fermentable) oligomer of $\beta$-D-fructose (obtained by inulin hydrolysis) possess the physiological effect on cholesterol while significantly lower serum triglyceride levels by decreasing postprandial cholesterolemia and triglyceridemia by $15 \%$ and $50 \%$, respectively [182]. The lipogenic decline in enzyme activity and very-low-density lipoprotein (VLDL), which contains the highest amounts of triglycerides particles contribute to this effect [183]. Moreover, FOS fermentation increases propionic acid in intestinal mucosa and in turn reduces levels of triacylglycerol (TAG) and associated hypercholesterolemia LDL and VLDL [23]. In human 
studies, the use of inulin and oligofructose as food supplements in normal and hyperlipidaemic conditions showed no effects on serum cholesterol or triglyceride. However, three investigations showed slight reduction in triacylglycerol, while four inspections cholesterol and triacylglycerol lowered significantly $[114,184]$. Inulin appears to be more suitable than oligofructose in reducing triglyceridemia while in animal studies, both oligofructose and inulin were equally active [185]. Based on these findings, prebiotics have been shown to affect hepatic lipid metabolism [185]. In a study of diabetic rats, simple carbohydrates were replaced with XOS in their diets and there was a drastic drop in serum cholesterol and TAG in diabetic rats while liver triacylglycerol increased to commensurate levels to that observed in healthy rats [186]. This was attributed to lipogenic enzyme inhibition, resulting from prebiotic fermentation in the gut by the action of propionate [15].

\section{Defense mechanism and immune regulation}

Consumption of functional food boosts the immune system [170]. Fermentation of saccharolytic metabolites, resulting from dietary intake is closely associated to be in contact with gut lymphoid tissues which cover the majority of the intestinal immune system [166, 170]. Products of FOS fermentation may modulate the GALT as well as the systemic immune system [171]. A concept of immunity suggested by Saad et al. (2013) showed that innate immune response can be activated by sugar moieties interacting synergistically with innate receptors on the host plasma membrane in dendritic cells and macrophages [185]. B-glucose oligosaccharide activates immune reactions by binding to macrophages receptors. Orally ingested oligofructose and inulin modulate immune system parameters such as IL- 10 and IFN- $\gamma$ natural killer cells activity, lymphocyte proliferation, intestinal $\operatorname{Ig} \mathrm{A}$, and increase polymeric immunoglobulin receptor expression in ileum and colon regulation [170]. Consumption of prebiotics fiber induces bifidogenic microflora as a result of short-chain fatty acid from fiber fermentation and direct contact with cytoplasmic components with immune cells [185]. 


\section{Antioxidant effect}

Antioxidants are natural or synthetic compounds that may delay or prevent oxidative stress caused by physiological oxidants [50]. Conventionally, the antioxidants are divided into two groups: the antioxidants that scavenge directly for active free radicals such as reactive oxygen species (ROS) or reactive nitrogen species (RNS), and antioxidants that inhibit oxidative stress $[151,187]$. Free radicals are customarily unsteady and originate from nitrogen (RNS), oxygen (ROS) and, sulfur (Reactive Sulphur Species: RSS) [188]. ROS, RNS, and RSS generation in radical and/or non-radical forms occur in humans and animal cells because of metabolic and physiological processes [189]. Moreover, ROS-induced free radicals from exogenous or endogenous sources can be injurious to the body cell biomolecules, causing impairment to cell functions and oxidative stress or apoptosis [190]. Free radicals have also been implicated in numerous pathologies including cardiovascular complications, neurodegenerative disorders as well as oncogenic complications [191].

Intake of inulin-type oligosaccharides, vitamin C, vitamin E, and carotenoids have been found to have the potential to minimize the harmful effects of reactive species [188]. Dietary intake of antioxidants such as tocopherol, carotenoids, and ascorbate are difficult to disentangle through epidemiological studies from other vital vitamins and ingredients in fruits and vegetables. Nevertheless, several studies published suggest that antioxidants are a major remedy for endogenous damage to DNA, lipids, and proteins [189, 192]. Antioxidants play a key role in immune system activation by causing the proliferation of B and T cells, natural killer cells, and lymphokine-activated killer cells that prevent the body defense mechanism from pathogens [193]. Supplementation with dietary antioxidants counteracts the oxidants thereby boosting the complement system [50].

\section{Antioxidants and cardiovascular disease}

Cardiovascular complications are associated with low concentrations of ascorbate, tocopherol, and $\beta$-carotene [194]. From cardiovascular studies, oxidative modifications of apolipoproteins B 100 play a key role in the recognition of low-density lipoprotein (LDL). LDL uptake by macrophage receptors leads to foam cell formation and atherosclerotic plaques [195]. Lipid 
peroxidation has been found to alter reactive products of apolipoprotein B 100, leading to a decrease in net charge, a modification that leads to its recognition by scavenger receptors [196].

Antioxidants have anticancer effects. During cell division, an unpaired lesion of DNA can lead to mutation. Hence, an overriding factor in mutagenesis and carcinogenesis occurs from continuous cell division which is a precursor of tumour cells [197]. An increase in cell division enhances mutagenesis. It is difficult for cancer to emerge in non-dividing cells. Antioxidant intake can decrease carcinogenesis and mutagenesis in two ways: by decreasing oxidative DNA damage and by decreasing cell division [193].

\section{Antioxidants and cataracts}

Most common ophthalmology procedures involve cataract removal. Taylor and Allen (1992) investigated the impressive evidence that cataracts have oxidative etiology and dietary antioxidants can prevent their formation in humans [198]. Findings from five epidemiological studies assessed the effect of dietary antioxidants on cataracts and showed the deterrent effect of ascorbate, tocopherol, and carotenoids. Those individuals placed on tocopherol or ascorbate supplements daily active ingredient vitamin E succinate (VES)-grafted-chitosan oligosaccharide had about one-third risk of developing cataracts [199-203]. Other factors causing oxidative stress include cigarette smoking and radiation [204]. The eye protein shows an increased level of methionine sulfoxide, and more than $60 \%$ oxidation occurs on methionine residues, causing cataracts. Decrease or abstinence from smoking and increase in dietary consumption of antioxidants is a promising strategy to reduce cataracts.

Various experimental models have been used to analyse the antioxidant potential of free radical scavengers and inhibitors. These models include 1,1- diphenyl-2-picrylhydrazyl (DPPH) method, which is used to evaluate the free radical scavenging ability of natural antioxidants in food and beverages [151, 205, 206]. Ferric reducing antioxidant power assay (FRAP) is based on the reduction of $\mathrm{Fe}^{3+}-\mathrm{TPTZ}$ complex to the ferrous form at low $\mathrm{pH}$. This reduction is monitored by measuring the absorption spectrophotometrically at $593 \mathrm{~nm}[207,208]$. Moreover, Ojwach et al. (2020) reported a nitric oxide assay (NO) using Griess reagent, where a purified FOS reduced NO along with the standard antioxidant in a concentration-dependent manner [50]. Macrophages 
play a crucial role in the generation of pro-inflammatory molecules including nitric oxide (NO). The inducible nitric oxide synthase enzyme (iNOS) synthesizes NO and the enzyme has been widely characterized to be an inducer of both chronic and acute inflammation [209]. Other assays described also include 2,2- azinobis (3-ethylbenzothiazoline 6-sulfonate) 2,2'-axino-bis-3ethylbenzothiazoline-6-sulfonic acid (ABTS), oxygen radical absorption capacity assay (ORAC) [210].

\section{Other applications}

Fructoligosaccharides employability as functional foods has led to their industrial applications in the food and beverage industry. In beverages, they are used in cocoa, fruit drinks, infant formulas and powdered milk as supplements $[88,166,177]$. In addition, these functional foods are used as probiotics in yoghurt and other milk products to create symbiotic products. Other current applications include puddings and sherbets, desserts such as jellies, confectioneries (chocolate), biscuits, pastries spread (jam), marmalades, and meat products such as fish paste and tofu [56, 211].

\section{Conclusions and future direction}

Biofunctional properties and health benefits of oligosaccharides have increased the importance of bioprospecting for novel, cheap and renewable bioresources for their production. FOS are synthesized in vitro from precursors such as sucrose using fructosyltransferase secreted by coprophilous fungi. Furthermore, IOS can also be produced from the enzymatic hydrolysis of inulin under controlled conditions. However, the main drawback of the production process is low yields of the oligosaccharides, amongst others. Exploration of other techniques including molecular methods to improve the efficiency of the enzymes involved in the synthesis of FOS and IOS is crucial. Further research on genome sequences of dung-inhabiting fungi is currently available. Among them is a classical model of Podospora anserine; the release of entire genome sequences will facilitate comprehension of various environmental interactions including their potential for metabolomics studies. Recombinant gene technology should be considered as a 
predominant promising approach to boost the yield of enzyme production at the industrial level. This application can be used in the cloning and expression of industrial enzymes in an optimized strain for biotechnological exploitation. Genome shuffling is one of such technologies that could be used to improve the specific activity of Ftase by amplifying its genetic diversity. There is a need to study the human gut microbiome beyond Bifidobacterium and Lactobacillus by evaluating certain areas of nutrition. The Nutrigenomics approach using molecular tools could be a starting point towards the future of biofunctional foods.

\section{Acknowledgment}

The authors would like to acknowledge IKS-National Research Foundation and the University of KwaZulu-Natal for funding this project.

\section{Conflict of Interest}

The authors declare that they have no conflict of interest.

\section{Funding}

Department of Science and Technology DST-National Research Foundation, Center in Indigenous Knowledge Systems (CIKS), South Africa.

\section{Author contributions:}

J.O conceived and wrote the original draft of the manuscript, review, and editing. AIA was responsible for editing; T.M and SM conceived the study, analysis, investigation, review, editing, and supervision.

Ethical approval: This article does not contain any studies with animals performed by any of the authors. 


\section{References}

1. Goldberg, I., Functional foods: designer foods, pharmafoods, nutraceuticals. 2012: Springer Science \& Business Media.

2. Roberfroid, M.B., Prebiotics and probiotics: are they functional foods? The American journal of clinical nutrition, 2000. 71(6): p. 1682S-1687S.

3. Kandylis, P., Grapes and Their Derivatives in Functional Foods. 2021, Multidisciplinary Digital Publishing Institute.

4. Collazo, N., et al., Health Promoting Properties of Bee Royal Jelly: Food of the Queens. Nutrients, 2021. 13(2): p. 543.

5. Davani-Davari, D., et al., Prebiotics: definition, types, sources, mechanisms, and clinical applications. Foods, 2019. 8(3): p. 92.

6. Gibson, G.R., et al., Dietary modulation of the human colonic microbiota: updating the concept of prebiotics. Nutrition research reviews, 2004. 17(2): p. 259-275.

7. Younis, K., S. Ahmad, and K. Jahan, Health benefits and application of prebiotics in foods. Journal of Food Processing \& Technology, 2015. 6(4): p. 1.

8. Zhang, J., et al., Enhancing fructooligosaccharides production by genetic improvement of the industrial fungus Aspergillus niger ATCC 20611. Journal of biotechnology, 2017. 249: p. 25-33.

9. Ahmad, A.M.R., et al., Prebiotics and iron bioavailability? Unveiling the hidden association-A review. Trends in Food Science \& Technology, 2021.

10. Barreteau, H., C. Delattre, and P. Michaud, Production of Oligosaccharides as Promising New Food Additive Generation. Food Technology \& Biotechnology, 2006. 44(3).

11. AlAli, M., et al., Nutraceuticals: Transformation of Conventional Foods into Health Promoters/Disease Preventers and Safety Considerations. Molecules, 2021. 26(9): p. 2540.

12. Kalra, E.K., Nutraceutical-definition and introduction. Aaps Pharmsci, 2003. 5(3): p. 2728.

13. Pandey, M., R.K. Verma, and S.A. Saraf, Nutraceuticals: new era of medicine and health. Asian J Pharm Clin Res, 2010. 3(1): p. 11-15. 
14. Pearson, K., Nutraceuticals and skin health: key benefits and protective properties. Journal of Aesthetic Nursing, 2018. 7(Sup1): p. 35-40.

15. Al-Sheraji, S.H., et al., Prebiotics as functional foods: A review. Journal of functional foods, 2013. 5(4): p. 1542-1553.

16. Belorkar, S.A. and A. Gupta, Oligosaccharides: a boon from nature's desk. Amb Express, 2016. 6(1): p. 1-11.

17. Michel, M.R., et al., Fructosyltransferase sources, production, and applications for prebiotics production, in Probiotics and Prebiotics in Human Nutrition and Health. 2016, IntechOpen. p. 169-90.

18. Ojwach, J., et al., Fructosyltransferase and inulinase production by indigenous coprophilous fungi for the biocatalytic conversion of sucrose and inulin into oligosaccharides. Biocatalysis and Agricultural Biotechnology, 2020. 30: p. 101867.

19. Yan, Y.L., Y. Hu, and M.G. Gänzle, Prebiotics, FODMAPs and dietary fiber-conflicting concepts in development of functional food products? Current Opinion in Food Science, 2018. 20: p. 30-37.

20. Hernández, L., et al., Fructooligosaccharides production by Schedonorus arundinaceus sucrose: sucrose 1-fructosyltransferase constitutively expressed to high levels in Pichia pastoris. Journal of biotechnology, 2018. 266: p. 59-71.

21. Mutanda, T., et al., Microbial enzymatic production and applications of short-chain fructooligosaccharides and inulooligosaccharides: recent advances and current perspectives. Journal of Industrial Microbiology and Biotechnology, 2014. 41(6): p. 893906.

22. Ganaie, M.A. and U.S. Gupta, Recycling of cell culture and efficient release of intracellular fructosyltransferase by ultrasonication for the production of fructooligosaccharides. Carbohydrate polymers, 2014. 110: p. 253-258.

23. Bali, V., et al., Fructo-oligosaccharides: production, purification and potential applications. Critical reviews in food science and nutrition, 2015. 55(11): p. 1475-1490.

24. Roberfroid, M.B. and N.M. Delzenne, Dietary fructans. Annual review of nutrition, 1998. 18(1): p. 117-143.

25. Scholz-Ahrens, K.E. and J. Schrezenmeir, Inulin, oligofructose and mineral metabolismexperimental data and mechanism. British Journal of Nutrition, 2002. 87(S2): p. S179S186. 
26. Scholz-Ahrens, K.E., Y. Açil, and J. Schrezenmeir, Effect of oligofructose or dietary calcium on repeated calcium and phosphorus balances, bone mineralization and trabecular structure in ovariectomized rats. British Journal of Nutrition, 2002. 88(4): p. 365-377.

27. Prapulla, S., V. Subhaprada, and N. Karanth, Microbial production of oligosaccharides: $a$ review. 2000.

28. Antosova, M. and M. Polakovic, Fructosyltransferases: the enzymes catalyzing production of fructooligosaccharides. Chemical papers-slovak Academy of Sciences, 2002. 55(6): p. 350-358.

29. Teferra, T.F., Possible actions of inulin as prebiotic polysaccharide: A review. Food Frontiers, 2021.

30. Ziemer, C.J. and G.R. Gibson, An overview of probiotics, prebiotics and synbiotics in the functional food concept: perspectives and future strategies. International Dairy Journal, 1998. 8(5-6): p. 473-479.

31. Sangeetha, P., M. Ramesh, and S. Prapulla, Recent trends in the microbial production, analysis and application of fructooligosaccharides. Trends in food science \& technology, 2005. 16(10): p. 442-457.

32. Goulas, A., G. Tzortzis, and G.R. Gibson, Development of a process for the production and purification of $\alpha$-and $\beta$-galactooligosaccharides from Bifidobacterium bifidum NCIMB 41171. International Dairy Journal, 2007. 17(6): p. 648-656.

33. Lecerf, J.-M., et al., Xylo-oligosaccharide (XOS) in combination with inulin modulates both the intestinal environment and immune status in healthy subjects, while XOS alone only shows prebiotic properties. British Journal of Nutrition, 2012. 108(10): p. 18471858.

34. Fan, R., et al., Process Design for the Production of Prebiotic Oligosaccharides in an Enzyme Membrane Bioreactor: Interaction between Enzymatic Reaction and Membrane Filtration. Chemie Ingenieur Technik, 2021. 93(1-2): p. 306-310.

35. Ojwach, J., et al., Purification and biochemical characterization of an extracellular fructosyltransferase enzyme from Aspergillus niger sp. XOBP48: implication in fructooligosaccharide production. 3 Biotech, 2020. 10(10): p. 1-12. 
36. Wang, J., et al., Continuous production of fructooligosaccharides by recycling of the thermal-stable $\beta$-fructofuranosidase produced by Aspergillus niger. Biotechnology Letters, 2021. 43(6): p. 1175-1182.

37. Zhao, L., et al., Biological strategies for oligo/polysaccharide synthesis: biocatalyst and microbial cell factory. Carbohydrate Polymers, 2021: p. 117695.

38. Farouq, A.A., et al., Isolation and characterization of Coprophilous cellulolytic fungi from Asian elephant (Elephas maximus) dung. J Biol Agr Healthc, 2012. 2(7): p. 44-51.

39. Eliasson, U., Coprophilous myxomycetes: Recent advances and future research directions. Fungal diversity, 2013. 59(1): p. 85-90.

40. Sarrocco, S., Dung-inhabiting fungi: a potential reservoir of novel secondary metabolites for the control of plant pathogens. Pest management science, 2016. 72(4): p. 643-652.

41. Baker, A.G., S.A. Bhagwat, and K.J. Willis, Do dung fungal spores make a good proxy for past distribution of large herbivores? Quaternary Science Reviews, 2013. 62: p. 2131.

42. Richardson, M.J., Diversity and occurrence of coprophilous fungi. Mycological Research, 2001. 105(4): p. 387-402.

43. López-Sáez, J.A. and L. López-Merino, Coprophilous fungi as a source of information of anthropic activities during the Prehistory in the Amblés Valley (Ávila, Spain): the archaeopalynological record. Revista Española de Micropaleontología, 2007. 39(1-2): p. 103-116.

44. Johnson, C.N., et al., Using dung fungi to interpret decline and extinction of megaherbivores: problems and solutions. Quaternary Science Reviews, 2015. 110: p. 107-113.

45. Calaça, F. and S. Xavier-Santos, New records of coprophilous ascomycetes (Fungi: Ascomycota) from Brazil and Neotropical Region. Check List, 2016. 12: p. 1.

46. Melo, R.F.R., et al., Coprophilous fungi from Brazil: updated identification keys to all recorded species. Phytotaxa, 2020. 436(2): p. 104-124.

47. Richardson, M.J., The coprophilous succession. Fungal Diversity, 2002. 10(1): p. 1-111.

48. Peterson, R.A., et al., Fungi from koala (Phascolarctos cinereus) faeces exhibit a broad range of enzyme activities against recalcitrant substrates. Letters in applied microbiology, 2009. 48(2): p. 218-225. 
49. Selinger, L., C. Forsberg, and K.-J. Cheng, The rumen: a unique source of enzymes for enhancing livestock production. Anaerobe, 1996. 2(5): p. 263-284.

50. Ojwach, J., et al., Fructooligosaccharides synthesized by fructosyltransferase from an indigenous coprophilous Aspergillus niger strain XOBP48 exhibits antioxidant activity. Bioactive Carbohydrates and Dietary Fibre, 2020. 24: p. 100238.

51. Shinde, V.K. and K.R. Vamkudoth, Maltooligosaccharide forming amylases and their applications in food and pharma industry. Journal of Food Science and Technology, 2021: p. 1-12.

52. Kothari, D., S. Patel, and A. Goyal, Therapeutic spectrum of nondigestible oligosaccharides: overview of current state and prospect. Journal of food science, 2014. 79(8): p. R1491-R1498.

53. Sangeetha, P., Microbial production of fructooligosaccharides. 2003, University of Mysore.

54. Apolinar-Valiente, R., P. Williams, and T. Doco, Recent advances in the knowledge of wine oligosaccharides. Food Chemistry, 2021. 342: p. 128330.

55. Ibrahim, O.O., Functional oligo-saccharides: chemicals structure, manufacturing, health benefits, applications and regulations. J. Food Chem. Nanotechnol, 2018. 4: p. 65-76.

56. Mussatto, S.I. and I.M. Mancilha, Non-digestible oligosaccharides: A review. Carbohydrate polymers, 2007. 68(3): p. 587-597.

57. Alméciga-Díaz, C.J., et al., Computational analysis of the fructosyltransferase enzymes in plants, fungi and bacteria. Gene, 2011. 484(1-2): p. 26-34.

58. Patel, S. and A. Goyal, Functional oligosaccharides: production, properties and applications. World Journal of Microbiology and Biotechnology, 2011. 27(5): p. 11191128.

59. Roberfroid, M. and J. Slavin, Nondigestible oligosaccharides. Critical Reviews in Food Science and Nutrition., 2000. 40(6): p. 461-480.

60. Kwak, N.-S. and D.J. Jukes, Functional foods. Part 1: the development of a regulatory concept. Food Control, 2001. 12(2): p. 99-107.

61. Roberfroid, M., Prebiotics: the concept revisited. The Journal of nutrition, 2007. 137(3): p. $830 \mathrm{~S}-837 \mathrm{~S}$.

62. Raman, R., et al., Glycomics: an integrated systems approach to structure-function relationships of glycans. Nature methods, 2005. 2(11): p. 817-824. 
63. Bersaneti, G.T., et al., Co-production of Fructooligosaccharides and Levan by Levansucrase from Bacillus subtilis natto with Potential Application in the Food Industry. Applied biochemistry and biotechnology, 2018. 184(3): p. 838-851.

64. Yoshida, M., Fructan Structure and Metabolism in Overwintering Plants. Plants, 2021. 10(5): p. 933.

65. Manosroi, J., N. Khositsuntiwong, and A. Manosroi, Biological activities of fructooligosaccharide (FOS)-containing Coix lachryma-jobi Linn. extract. Journal of food science and technology, 2014. 51(2): p. 341-346.

66. Meyer, T.S.M., et al., Biotechnological production of oligosaccharides-applications in the food industry. food production and industry. InTech, 2015: p. 25-78.

67. Benkeblia, N., Fructooligosaccharides and fructans analysis in plants and food crops. Journal of Chromatography A, 2013. 1313: p. 54-61.

68. Kango, N. and S.C. Jain, Production and properties of microbial inulinases: recent advances. Food Biotechnology, 2011. 25(3): p. 165-212.

69. Fernandes, M.R.V.S. and B. Jiang, Research Article Fungal Inulinases as Potential Enzymes for Application in the Food Industry. Advance Journal of Food Science and Technology, 2013. 5(8): p. 1031-1042.

70. Rawat, H.K., et al., Biotechnological potential of microbial inulinases: recent perspective. Critical reviews in food science and nutrition, 2017. 57(18): p. 3818-3829.

71. Flamm, G., et al., Inulin and oligofructose as dietary fiber: a review of the evidence. Critical reviews in food science and nutrition, 2001. 41(5): p. 353-362.

72. Singh, R., T. Singh, and J.F. Kennedy, Enzymatic synthesis of fructooligosaccharides from inulin in a batch system. Carbohydrate Polymer Technologies and Applications, 2020. 1: p. 100009.

73. Pérez, E.R., et al., Fructooligosaccharides production by immobilized Pichia pastoris cells expressing Schedonorus arundinaceus sucrose: sucrose 1-fructosyltransferase. Journal of Industrial Microbiology and Biotechnology, 2021.

74. Lorenzoni, A.S., et al., Fructooligosaccharides synthesis by highly stable immobilized $\beta$ fructofuranosidase from Aspergillus aculeatus. Carbohydrate polymers, 2014. 103: p. 193-197. 
75. Nemukula, A., et al., Response surface methodology: Synthesis of short chain fructooligosaccharides with a fructosyltransferase from Aspergillus aculeatus. Bioresource Technology, 2009. 100(6): p. 2040-2045.

76. Russell, R., A.C. Donald, and C. Douglas, Fructosyltransferase activity of a glucanbinding protein from Streptococcus mutans. Microbiology, 1983. 129(10): p. 3243-3250.

77. Burne, R.A., et al., Expression, purification, and characterization of an exo-beta-Dfructosidase of Streptococcus mutans. Journal of bacteriology, 1987. 169(10): p. 45074517.

78. Shiroza, T. and H.K. Kuramitsu, Sequence analysis of the Streptococcus mutans fructosyltransferase gene and flanking regions. Journal of bacteriology, 1988. 170(2): p. 810-816.

79. Cheetham, P.S., A.J. Hacking, and M. Vlitos, Synthesis of novel disaccharides by a newly isolated fructosyl transferase from Bacillus subtilis. Enzyme and microbial technology, 1989. 11(4): p. 212-219.

80. Park, J.-P., T.-K. Oh, and J.-W. Yun, Purification and characterization of a novel transfructosylating enzyme from Bacillus macerans EG-6. Process Biochemistry, 2001. 37(5): p. 471-476.

81. Ooi, M.C., The preparation of common prebiotic oligosaccharides with defined degree of polymerization. 2021.

82. L'Hocine, L., et al., Purification and partial characterization of fructosyltransferase and invertase from Aspergillus niger AS0023. Journal of biotechnology, 2000. 81(1): p. 73-84.

83. Saminathan, M., et al., Effect of prebiotic oligosaccharides on growth of Lactobacillus strains used as a probiotic for chickens. African Journal of Microbiology Research, 2011. 5(1): p. 57-64.

84. Dominguez, A.L., et al., An overview of the recent developments on fructooligosaccharide production and applications. Food and Bioprocess Technology, 2014. 7(2): p. 324-337.

85. Ganaie, M.A., A. Lateef, and U.S. Gupta, Enzymatic trends of fructooligosaccharides production by microorganisms. Applied biochemistry and biotechnology, 2014. 172(4): p. 2143-2159.

86. Brownawell, A.M., et al., Prebiotics and the health benefits of fiber: current regulatory status, future research, and goals. The Journal of nutrition, 2012. 142(5): p. 962-974. 
87. Ganaie, M.A., U.S. Gupta, and N. Kango, Screening of biocatalysts for transformation of sucrose to fructooligosaccharides. Journal of Molecular Catalysis B: Enzymatic, 2013. 97: p. 12-17.

88. Sabater-Molina, M., et al., Dietary fructooligosaccharides and potential benefits on health. Journal of physiology and biochemistry, 2009. 65(3): p. 315-328.

89. Wang, T.-H., Synthesis of neofructooligosaccharides. Organic chemistry insights, 2015. 5: p. 1.

90. Barclay, T., et al., Inulin-a versatile polysaccharide with multiple pharmaceutical and food chemical uses. Journal of Excipients and Food Chemicals, 2016. 1(3): p. 1132.

91. Ponce, J.A., et al., Physical-Chemical and non-linear rheological properties of aqueous solutions of agave fructans. e-Gnosis, 2008. 6: p. 1-23.

92. Niness, K.R., Inulin and oligofructose: what are they? The Journal of nutrition, 1999. 129(7): p. 1402S-1406S.

93. Beikzadeh, M., et al., Effect of inulin, oligofructose and oligofructose-enriched inulin on physicochemical, staling, and sensory properties of prebiotic cake. 2018.

94. Cherbut, C., Inulin and oligofructose in the dietary fibre concept. British Journal of Nutrition, 2002. 87(S2): p. S159-S162.

95. Liang, X., et al., Fermentative Production of Fructo-Oligosaccharides Using Aureobasidium pullulans: Effect of Dissolved Oxygen Concentration and Fermentation Mode. Molecules, 2021. 26(13): p. 3867.

96. Viniegra-González, G., et al., Advantages of fungal enzyme production in solid state over liquid fermentation systems. Biochemical Engineering Journal, 2003. 13(2-3): p. 157-167.

97. Das, K. and A.K. Mukherjee, Comparison of lipopeptide biosurfactants production by Bacillus subtilis strains in submerged and solid state fermentation systems using a cheap carbon source: some industrial applications of biosurfactants. Process Biochemistry, 2007. 42(8): p. 1191-1199.

98. Mussatto, S.I., et al., Economic analysis and environmental impact assessment of three different fermentation processes for fructooligosaccharides production. Bioresource technology, 2015. 198: p. 673-681.

99. Couto, S.R. and M.A. Sanromán, Application of solid-state fermentation to food industry - a review. Journal of Food Engineering, 2006. 76(3): p. 291-302. 
100. Mussatto, S.I., et al., Maximization of fructooligosaccharides and $\beta$-fructofuranosidase production by Aspergillus japonicus under solid-state fermentation conditions. Food and Bioprocess Technology, 2013. 6(8): p. 2128-2134.

101. Muñiz-Márquez, D.B., et al., Enhancement of fructosyltransferase and fructooligosaccharides production by A. oryzae DIA-MF in Solid-State Fermentation using aguamiel as culture medium. Bioresource technology, 2016. 213: p. 276-282.

102. Rustiguel, C.B., et al., Biochemical properties of an extracellular $\beta$-D-fructofuranosidase II produced by Aspergillus phoenicis under Solid-Sate Fermentation using soy bran as substrate. Electronic Journal of Biotechnology, 2011. 14(2): p. 2-2.

103. Mussatto, S.I., et al., Fructooligosaccharides and $\beta$-fructofuranosidase production by Aspergillus japonicus immobilized on lignocellulosic materials. Journal of Molecular Catalysis B: Enzymatic, 2009. 59(1-3): p. 76-81.

104. Mazutti, M., et al., Production of inulinase by solid-state fermentation: effect of process parameters on production and preliminary characterization of enzyme preparations. Bioprocess and biosystems engineering, 2007. 30(5): p. 297-304.

105. Ashokkumar, B., N. Kayalvizhi, and P. Gunasekaran, Optimization of media for $\beta$ fructofuranosidase production by Aspergillus niger in submerged and solid state fermentation. Process Biochemistry, 2001. 37(4): p. 331-338.

106. Singh, R., et al., Biocatalytic strategies for the production of high fructose syrup from inulin. Bioresource technology, 2018. 260: p. 395-403.

107. Li, X., et al., A Novel Inulin-Mediated Ethanol Precipitation Method for Separating Endo-Inulinase From Inulinases for Inulooligosaccharides Production From Inulin. Frontiers in Bioengineering and Biotechnology, 2021. 9.

108. Singh, R.S., R.P. Singh, and J.F. Kennedy, Recent insights in enzymatic synthesis of fructooligosaccharides from inulin. International Journal of Biological Macromolecules, 2016. 85: p. 565-572.

109. Roberfroid, M.B., Introducing inulin-type fructans. British journal of nutrition, 2005. 93(S1): p. S13-S25.

110. Roberfroid, M., Inulin-type fructans: functional food ingredients. 2004: CRC Press.

111. Singh, R. and T. Singh, Fructooligosaccharides Production from Inulin by Immobilized Endoinulinase on 3-Aminopropyltriethoxysilane Functionalized Halloysite Nanoclay. Catalysis Letters, 2021: p. 1-23. 
112. He, M., et al., Enhanced expression of endoinulinase from Aspergillus niger by codon optimization in Pichia pastoris and its application in inulooligosaccharide production. Journal of industrial microbiology and biotechnology, 2014. 41(1): p. 105-114.

113. Rawat, H.K., M.A. Ganaie, and N. Kango, Production of inulinase, fructosyltransferase and sucrase from fungi on low-value inulin-rich substrates and their use in generation of fructose and fructo-oligosaccharides. Antonie Van Leeuwenhoek, 2015. 107(3): p. 799811.

114. Li, L., P. Li, and L. Xu, Assessing the effects of inulin-type fructan intake on body weight, blood glucose, and lipid profile: A systematic review and meta-analysis of randomized controlled trials. Food science \& nutrition, 2021. 9(8): p. 4598-4616.

115. Chi, Z., et al., Inulinase-expressing microorganisms and applications of inulinases. Applied Microbiology and Biotechnology, 2009. 82(2): p. 211-220.

116. Singh, R.S., K. Chauhan, and J.F. Kennedy, A panorama of bacterial inulinases: production, purification, characterization and industrial applications. International journal of biological macromolecules, 2017. 96: p. 312-322.

117. Trollope, K.M., Engineering a fungal $\beta$-fructofuranosidase. 2015, Stellenbosch: Stellenbosch University.

118. Apolinário, A.C., et al., Inulin-type fructans: A review on different aspects of biochemical and pharmaceutical technology. Carbohydrate polymers, 2014. 101: p. 368-378.

119. Khuenpet, K., et al., Inulin powder production from Jerusalem artichoke (Helianthus tuberosus L.) tuber powder and its application to commercial food products. Journal of Food Processing and Preservation, 2017. 41(4): p. e13097.

120. Tomotani, E.J. and M. Vitolo, Production of high-fructose syrup using immobilized invertase in a membrane reactor. Journal of food engineering, 2007. 80(2): p. 662-667.

121. Cho, Y.J., et al., Production of inulooligosaccharides from inulin by a dual endoinulinase system. Enzyme and Microbial Technology, 2001. 29(6-7): p. 428-433.

122. Kim, H.-C., et al., Inulooligosaccharide production from inulin by Saccharomyces cerevisiae strain displaying cell-surface endoinulinase. Journal of microbiology and biotechnology, 2006. 16(3): p. 360-367.

123. Schmid, A., et al., Industrial biocatalysis today and tomorrow. nature, 2001. 409(6817): p. 258-268. 
124. de Oliveira Kuhn, G., et al., Synthesis of fructooligosaccharides from Aspergillus niger commercial inulinase immobilized in montmorillonite pretreated in pressurized propane and LPG. Applied biochemistry and biotechnology, 2013. 169(3): p. 750-760.

125. Dantas, J.M.d.M., et al., Purification of chitosanases produced by Bacillus toyonensis CCT 7899 and functional oligosaccharides production. Preparative Biochemistry \& Biotechnology, 2021: p. 1-9.

126. Mathur, A. and D. Sadana, INULINASE: MICROBIAL ORIGIN TO FOOD APPLICATIONS. 2021.

127. YAZICI, S.Ö., et al., Response Surface Methodology-Based optimization of Inulinase Production from New Bacillus Isolates. Sakarya University Journal of Science, 2021. 25(4): p. 1086-1101.

128. Guío, F., et al., Recent trends in fructooligosaccharides production. Recent patents on food, nutrition \& agriculture, 2009. 1(3): p. 221-230.

129. Corrado, I., et al., Optimization of Inulin Hydrolysis by Penicillium lanosocoeruleum Inulinases and Efficient Conversion Into Polyhydroxyalkanoates. Frontiers in bioengineering and biotechnology, 2021. 9: p. 108.

130. Cho, Y.J. and J.W. Yun, Purification and characterization of an endoinulinase from Xanthomonas oryzae No. 5. Process Biochemistry, 2002. 37(11): p. 1325-1331.

131. Singh, R., T. Singh, and A. Pandey, Production of fungal endoinulinase in a stirred tank reactor and fructooligosaccharides preparation by crude endoinulinase. Bioresource Technology Reports, 2021. 15: p. 100743.

132. Maiorano, A.E., et al., Microbial production of fructosyltransferases for synthesis of prebiotics. Biotechnology letters, 2008. 30(11): p. 1867-1877.

133. Lateef, A., et al., Production of fructosyltransferase by a local isolate of Aspergillus niger in both submerged and solid substrate media. Acta alimentaria, 2012. 41(1): p. 100-117.

134. Yoshikawa, J., et al., Multiple $\beta$-fructofuranosidases by Aureobasidium pullulans DSM2404 and their roles in fructooligosaccharide production. FEMS Microbiology Letters, 2006. 265(2): p. 159-163.

135. Chi, Z., et al., Bioproducts from Aureobasidium pullulans, a biotechnologically important yeast. Applied microbiology and biotechnology, 2009. 82(5): p. 793-804. 
136. Kurakake, M., et al., Production of fructooligosaccharides by $\beta$-fructofuranosidases from Aspergillus oryzae KB. Journal of agricultural and food chemistry, 2010. 58(1): p. 488492.

137. Mashita, M. and S. Hatijah, Production of fructosyltransferase by Penicillium simplicissimum in batch culture. African Journal of Biotechnology, 2014. 13(46).

138. $\mathrm{Xu}, \mathrm{Q}$,, et al., Purification and biochemical characterization of a novel $\beta$ fructofuranosidase from Penicillium oxalicum with transfructosylating activity producing neokestose. Process Biochemistry, 2015. 50(8): p. 1237-1246.

139. Ademakinwa, A.N., Z.A. Ayinla, and F.K. Agboola, Strain improvement and statistical optimization as a combined strategy for improving fructosyltransferase production by Aureobasidium pullulans NAC8. Journal of Genetic Engineering and Biotechnology, 2017. 15(2): p. 345-358.

140. Jayalakshmi, J., A. Mohamed Sadiqa, and V. Sivakumarb, Microbial enzymatic production of fructooligosaccharides from sucrose in agricultural harvest. Asian J. Microbiol. Biotechnol. Environ. Sci, 2021. 23: p. 84-88.

141. Michel, M.R., et al., Fructosyltransferase production by Aspergillus oryzae BM-DIA using solid-state fermentation and the properties of its nucleotide and protein sequences. Folia Microbiologica, 2021. 66(3): p. 469-481.

142. Van Balken, J., et al., Production of 1-kestose with intact mycelium of Aspergillus phoenicis containing sucrose-1 F-fructosyltransferase. Applied microbiology and biotechnology, 1991. 35(2): p. 216-221.

143. Barthomeuf, C. and H. Pourrat, Production of high-content fructo-oligosaccharides by an enzymatic system from Penicillium rugulosum. Biotechnology letters, 1995. 17(9): p. 911916.

144. Belorkar, S.A., A. Gupta, and V. Rai, Screening of microbial isolates for extracellular fructosyltransferase production. African Journal of Microbiology Research, 2015. 9(10): p. 730-735.

145. Chen, W.-c. and C.-h. Liu, Production of $\beta$-fructofuranosidase by Aspergillus japonicus. Enzyme and Microbial Technology, 1996. 18(2): p. 153-160.

146. Madlov, A., et al., Screening of microorganisms for transfructosylating activity and optimization of biotransformation of sucrose to fructooligosaccharides. CHEMICAL PAPERS-SLOVAK ACADEMY OF SCIENCES, 2000. 53(6): p. 366-369. 
147. Fernandez, R.C., et al., Screening of $\beta$-fructofuranosidase-producing microorganisms and effect of $\mathrm{pH}$ and temperature on enzymatic rate. Applied microbiology and biotechnology, 2007. 75(1): p. 87-93.

148. Dominguez, A., et al., New and simple plate test for screening relative transfructosylation activity of fungi. Revista iberoamericana de micología, 2006. 23(3): p. 189-191.

149. Guimarães, L.H.S., et al., Screening of filamentous fungi for production of enzymes of biotechnological interest. Brazilian Journal of Microbiology, 2006. 37: p. 474-480.

150. Maugeri, F. and S. Hernalsteens, Screening of yeast strains for transfructosylating activity. Journal of Molecular Catalysis B: Enzymatic, 2007. 49(1-4): p. 43-49.

151. Lama, A., Screening of fungi with potential for producing fructooligosaccharides with enhanced bioactivity. 2017.

152. Hicke, H.-G., et al., Novel enzyme-membrane reactor for polysaccharide synthesis. Journal of membrane science, 1999. 161(1-2): p. 239-245.

153. Van Hijum, S., et al., Biochemical and molecular characterization of a levansucrase from Lactobacillus reuteri. Microbiology, 2004. 150(3): p. 621-630.

154. Song, D.D. and N.A. Jacques, Mutation of aspartic acid residues in the fructosyltransferase of Streptococcus salivarius ATCC 25975. Biochemical Journal, 1999. 344(1): p. 259-264.

155. Song, D.D. and N.A. Jacques, Purification and enzymic properties of the fructosyltransferase of Streptococcus salivarius ATCC 25975. Biochemical Journal, 1999. 341(2): p. 285-291.

156. Dahech, I., et al., Partial purification of a Bacillus licheniformis levansucrase producing levan with antitumor activity. International journal of biological macromolecules, 2012. 51(3): p. 329-335.

157. Porras-Domínguez, J.R., et al., Levan-type FOS production using a Bacillus licheniformis endolevanase. Process Biochemistry, 2014. 49(5): p. 783-790.

158. Bekers, M., et al., Fructooligosaccharide and levan producing activity of Zymomonas mobilis extracellular levansucrase. Process Biochemistry, 2002. 38(5): p. 701-706.

159. Sheu, D.C., et al., Production of fructooligosaccharides in high yield using a mixed enzyme system of $\beta$-fructofuranosidase and glucose oxidase. Biotechnology Letters, 2001. 23(18): p. 1499-1503. 
160. van Hijum, S.A., et al., Purification of a novel fructosyltransferase from Lactobacillus reuteri strain 121 and characterization of the levan produced. FEMS microbiology letters, 2001. 205(2): p. 323-328.

161. van Hijum, S.A.F.T., Fructosyltransferases of Lactobacillus reuteri: characterization of genes, enzymes, and fructan polymers. 2004.

162. Naidoo, K., et al., Purification and Characterization of an Endoinulinase from Xanthomonas campestris pv. phaseoli KM 24 Mutant. Food technology and biotechnology, 2015. 53(2): p. 146-153.

163. Pandey, A., et al., Recent developments in microbial inulinases. Applied biochemistry and biotechnology, 1999. 81(1): p. 35-52.

164. Gao, L., et al., Single-cell protein production from Jerusalem artichoke extract by a recently isolated marine yeast Cryptococcus aureus $G 7 a$ and its nutritive analysis. Applied microbiology and biotechnology, 2007. 77(4): p. 825-832.

165. Jing, W., et al., Production and separation of exo-and endoinulinase from Aspergillus ficuum. Process Biochemistry, 2003. 39(1): p. 5-11.

166. Sharma, R., et al., Barley-based probiotic food mixture: health effects and future prospects. Critical Reviews in Food Science and Nutrition, 2021: p. 1-15.

167. Kaprasob, R., et al., B vitamins and prebiotic fructooligosaccharides of cashew apple fermented with probiotic strains Lactobacillus spp., Leuconostoc mesenteroides and Bifidobacterium longum. Process biochemistry, 2018. 70: p. 9-19.

168. Cummings, J.H. and G.T. Macfarlane, Gastrointestinal effects of prebiotics. British Journal of Nutrition, 2002. 87(S2): p. S145-S151.

169. Durieux, A., et al., Metabolism of chicory fructooligosaccharides by bifidobacteria. Biotechnology letters, 2001. 23(18): p. 1523-1527.

170. Barber, T.M., et al., The health benefits of dietary fibre. Nutrients, 2020. 12(10): p. 3209.

171. Schley, P. and C. Field, The immune-enhancing effects of dietary fibres and prebiotics. British Journal of Nutrition, 2002. 87(S2): p. S221-S230.

172. Candela, M., et al., Human intestinal microbiota: cross-talk with the host and its potential role in colorectal cancer. Critical reviews in microbiology, 2011. 37(1): p. 1-14.

173. Azcárate-Peril, M.A., M. Sikes, and J.M. Bruno-Bárcena, The intestinal microbiota, gastrointestinal environment and colorectal cancer: a putative role for probiotics in 
prevention of colorectal cancer? American Journal of Physiology-Gastrointestinal and Liver Physiology, 2011. 301(3): p. G401-G424.

174. Van Loo, J., The specificity of the interaction with intestinal bacterial fermentation by prebiotics determines their physiological efficacy. Nutrition research reviews, 2004. 17(1): p. 89-98.

175. Scharlau, D., et al., Mechanisms of primary cancer prevention by butyrate and other products formed during gut flora-mediated fermentation of dietary fibre. Mutation Research/Reviews in Mutation Research, 2009. 682(1): p. 39-53.

176. Sharma, V., et al., Probiotics and Prebiotics Having Broad Spectrum Anticancer Therapeutic Potential: Recent Trends and Future Perspectives. Current Pharmacology Reports, 2021: p. 1-13.

177. Thum, C., et al., Effects of Prenatal Consumption of Caprine Milk Oligosaccharides on Mice Mono-associated with Bifidobacterium Bifidum (AGR2166). The open microbiology journal, 2017. 11: p. 105.

178. Yamamoto, Y., et al., Effect of High Fat and Fructo-Oligosaccharide Consumption on Immunoglobulin A in Saliva and Salivary Glands in Rats. Nutrients, 2021. 13(4): p. 1252.

179. Scholz-Ahrens, K.E., et al., Prebiotics, probiotics, and synbiotics affect mineral absorption, bone mineral content, and bone structure. The Journal of nutrition, 2007. 137(3): p. 838S-846S.

180. Bornet, F., et al., Nutritional aspects of short-chain fructooligosaccharides: natural occurrence, chemistry, physiology and health implications. Digestive and liver disease, 2002. 34: p. S111-S120.

181. de Cássia Freitas, K., O.M.S. Amancio, and M.B. de Morais, High-performance inulin and oligofructose prebiotics increase the intestinal absorption of iron in rats with iron deficiency anaemia during the growth phase. British Journal of Nutrition, 2012. 108(6): p. 1008-1016.

182. Kok, N., et al., Involvement of lipogenesis in the lower VLDL secretion induced by oligofructose in rats. British Journal of Nutrition, 1996. 76(6): p. 881-890.

183. Yamamoto, Y., et al., In vitro digestibility and fermentability of levan and its hypocholesterolemic effects in rats. The Journal of nutritional biochemistry, 1999. 10(1): p. 13-18. 
184. Nie, Y. and F. Luo, Dietary Fiber: An Opportunity for a Global Control of Hyperlipidemia. Oxidative Medicine and Cellular Longevity, 2021. 2021.

185. Saad, N., et al., An overview of the last advances in probiotic and prebiotic field. LWTFood Science and Technology, 2013. 50(1): p. 1-16.

186. Imaizumi, K., et al., Effects of xylooligosaccharides on blood glucose, serum and liver lipids and cecum short-chain fatty acids in diabetic rats. Agricultural and Biological Chemistry, 1991. 55(1): p. 199-205.

187. Guo, C., et al., Antioxidant activities of peel, pulp and seed fractions of common fruits as determined by FRAP assay. Nutrition research, 2003. 23(12): p. 1719-1726.

188. Aslani, B.A. and S. Ghobadi, Studies on oxidants and antioxidants with a brief glance at their relevance to the immune system. Life sciences, 2016. 146: p. 163-173.

189. Galano, A., D.-X. Tan, and R.J. Reiter, Melatonin: a versatile protector against oxidative DNA damage. Molecules, 2018. 23(3): p. 530.

190. Fang, Y.-Z., S. Yang, and G. Wu, Free radicals, antioxidants, and nutrition. Nutrition, 2002. 18(10): p. 872-879.

191. Battin, E.E. and J.L. Brumaghim, Antioxidant activity of sulfur and selenium: a review of reactive oxygen species scavenging, glutathione peroxidase, and metal-binding antioxidant mechanisms. Cell biochemistry and biophysics, 2009. 55(1): p. 1-23.

192. Czarnocka, W. and S. Karpiński, Friend or foe? Reactive oxygen species production, scavenging and signaling in plant response to environmental stresses. Free Radical Biology and Medicine, 2018. 122: p. 4-20.

193. Ames, B.N., M.K. Shigenaga, and T.M. Hagen, Oxidants, antioxidants, and the degenerative diseases of aging. Proceedings of the National Academy of Sciences, 1993. 90(17): p. 7915-7922.

194. Kang, Y., et al., Cardiovascular manifestations and treatment considerations in covid-19. Heart, 2020. 106(15): p. 1132-1141.

195. Salonen, J.T., et al., High stored iron levels are associated with excess risk of myocardial infarction in eastern Finnish men. Circulation, 1992. 86(3): p. 803-811.

196. Pryor, W.A., Free radicals and lipid peroxidation: what they are and how they got that way. Natural antioxidants in human health and disease, 1994: p. 1-24.

197. Weitzman, S.A. and L.I. Gordon, Inflammation and cancer: role of phagocyte-generated oxidants in carcinogenesis. 1990. 
198. Taylor, A., Role of Nutrients in Delaying Cataracts a. Annals of the New York Academy of Sciences, 1992. 669(1): p. 111-123.

199. Robertson, J.M., A.P. Donner, and J.R. Trevithick, Vitamin E Intake and Risk of Cataracts in Humans a. Annals of the New York Academy of Sciences, 1989. 570(1): p. 372-382.

200. Jacques, P.F. and L.T. Chylack Jr, Epidemiologic evidence of a role for the antioxidant vitamins and carotenoids in cataract prevention. The American journal of clinical nutrition, 1991. 53(1): p. 352S-355S.

201. Leske, M.C., L.T. Chylack, and S.-Y. Wu, The lens opacities case-control study: risk factors for cataract. Archives of ophthalmology, 1991. 109(2): p. 244-251.

202. Hankinson, S.E., et al., Nutrient intake and cataract extraction in women: a prospective study. British Medical Journal, 1992. 305(6849): p. 335-339.

203. Knekt, P., et al., Serum antioxidant vitamins and risk of cataract. British Medical Journal, 1992. 305(6866): p. 1392-1394.

204. Scandalios, J., Oxidative stress: molecular perception and transduction of signals triggering antioxidant gene defenses. Brazilian journal of medical and biological research, 2005. 38(7): p. 995-1014.

205. Deng, J., W. Cheng, and G. Yang, A novel antioxidant activity index (AAU) for natural products using the DPPH assay. Food Chemistry, 2011. 125(4): p. 1430-1435.

206. Floegel, A., et al., Comparison of ABTS/DPPH assays to measure antioxidant capacity in popular antioxidant-rich US foods. Journal of food composition and analysis, 2011. 24(7): p. 1043-1048.

207. Pellegrini, N., et al., Total antioxidant capacity of plant foods, beverages and oils consumed in Italy assessed by three different in vitro assays. The Journal of nutrition, 2003. 133(9): p. 2812-2819.

208. Müller, L., K. Fröhlich, and V. Böhm, Comparative antioxidant activities of carotenoids measured by ferric reducing antioxidant power (FRAP), ABTS bleaching assay ( $\alpha$ TEAC), DPPH assay and peroxyl radical scavenging assay. Food Chemistry, 2011. 129(1): p. 139-148.

209. Saha, K., et al., Evaluation of antioxidant and nitric oxide inhibitory activities of selected Malaysian medicinal plants. Journal of Ethnopharmacology, 2004. 92(2-3): p. 263-267. 
210. Dudonne, S., et al., Comparative study of antioxidant properties and total phenolic content of 30 plant extracts of industrial interest using DPPH, ABTS, FRAP, SOD, and ORAC assays. Journal of agricultural and food chemistry, 2009. 57(5): p. 1768-1774.

211. Crittenden, R.a. and M.J. Playne, Production, properties and applications of food-grade oligosaccharides. Trends in food science \& technology, 1996. 7(11): p. 353-361.

\section{FIGURE LEGENDS}

Fig. 1. Coprophilous fungi growing on herbivore dung substrata

Fig. 2. The structural composition of the main constituent of FOS (a) 1-kestose $\left(\mathrm{GF}_{2}\right)$, (b) 1nystose $\left(\mathrm{GF}_{3}\right)$, and (c) fructofuranosyl nystose $\left(\mathrm{GF}_{4}\right)$ Adopted from (Dominguez et al., 2014)

Fig. 3. FOS concentration in some natural foods mentioned according to the data of Environmental Protection Agency Dietary Risk (Sangeetha, 2003)

Fig. 4. Photographs of inulin producing plants a and $\mathbf{b}$ chicory flowery plants and its storage roots (Cichorium intibus), $\mathbf{c}, \mathbf{d}$ and f Jerusalem artichoke (Helianthus tuberosus), and e onions

Fig. 5. Degradation pattern of inulinase on inulin (Adapted from (Roberfroid et al., 1998)(Singh et al., 2017; Singh \& Singh, 2010) 
Fig. 6. Prevalence of pathogenic microbes (a) before and (b) after the uptake of inulin. The proliferation of Bifidobacteria after inulin intake showing prebiotic effect of inulooligosaccharide

Fig. 7 Beneficial impacts of Bifidobacteria accumulation in the colon 